\title{
Author Spotlight: Malorie Simons
}

\section{Malorie Simons ${ }^{1}$}

Published online: 15 July 2020

(c) Springer Science+Business Media, LLC, part of Springer Nature 2020

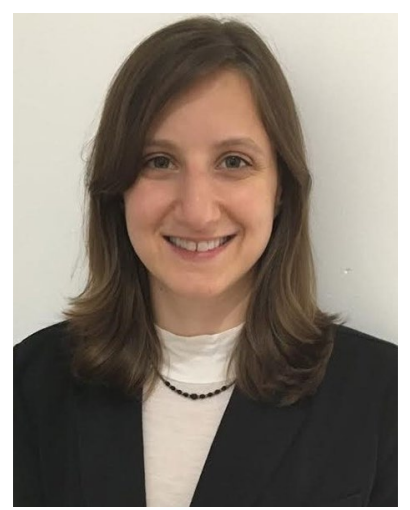

Malorie Simons is the current chief gastroenterology fellow at Johns Hopkins Hospital. She completed her residency and chief residency at Brown University Internal Medicine
Program and medical degree at Albany Medical College. Her research interests include gastrointestinal oncology including Barrett's esophagus and endoscopic resection of luminal malignancies. She is passionate about medical education and mentorship, particularly using social media platforms. She is currently applying for advanced endoscopy fellowships and is excited to build her career as an academic therapeutic endoscopist.

Publisher's Note Springer Nature remains neutral with regard to jurisdictional claims in published maps and institutional affiliations.
Malorie Simons

malorie.simons@gmail.com

1 Division of Gastroenterology and Hepatology, Johns Hopkins Hospital, Baltimore, MD, USA 